\title{
Technical study on the treatment of PCB production waste liquid and copper extraction
}

\author{
Chen $\mathrm{Ru}^{*}$ \\ College of Information Engineering, Shaanxi Institute of International Trade \&Commerce, Xi'an 712046, Shaanxi, China
}

\begin{abstract}
The increase in the use of electronic products has increased the production of printed circuit boards, in the production of circuit boards in the etching, micro-etching process, will produce a large number of high concentration of copper-containing etching waste liquid, these waste liquid, if directly discharged, will not only cause serious pollution to the human living environment, but also a large number of copper resources will be wasted. Therefore, this paper adopts a closed circulation system to treat the etching mother liquor discharged from the production line, extracting copper ions from the high concentration copper-containing etching liquid, and then returning the low concentration copper-containing etching liquid to the production line, which can not only effectively recover copper resources, but also make the pollution emission of etching waste liquid zero and not produce secondary pollution, so as to realize the harmony between human and nature by increasing production without increasing pollution. Development.
\end{abstract}

\section{Introduction}

PCB (printed circuit board) is an electronic component that uses electronic printing to etch on the surface of an insulated and heat-insulated copper-clad board that is not easily bent, leaving a mesh of tiny lines to connect various electronic components to form a predetermined circuit [1] and to achieve the role of relay transmission between electronic components, from smartphones to the small appliances we use every day, the core component of every electronic product is Circuit board. With the development of China's economy, the introduction of intelligent products, more accelerated the application of PCB.

At present, the development of the world's printed circuit board industry towards the high-end field of rapid progress. With the rapid development of HDI, flexible boards and high-grade IC carrier boards, a huge industry chain has been formed in the world, and has a relatively stable circuit board production base [2]. With the continuous emergence of electronic products, the use of circuit boards is also increasing dramatically, which in turn will lead to an increase in the amount of waste liquid discharged from the production of circuit boards, which contains a large number of metal substances, if directly discharged, will cause environmental pollution and a great waste of resources. Therefore, it is important to recycle and dispose of the waste liquid discharged during the production of circuit boards. This wasted resource is recycled [3], and the copper contained in it is extracted and turned into a treasure to achieve the maximum use of resources.

The laminate industry is an industry with a large capital requirement and relatively high concentration. Is the manufacture of printed circuit boards the most important material, in the printed circuit board production cost of copper clad board accounts for about $20 \%$ to $40 \%$ proportion. According to information, in recent years, China's copper laminate production capacity and output are steadily increasing, communications and computers are still when the main application areas of printed circuit boards, followed by automotive electronics, industrial electronics and other fields. Relatively speaking, the proportion is relatively low. The industry chain of the printed circuit board industry is shown in Figure 1.The application segment share of printed circuit boards in 2019 is shown in Figure 2.

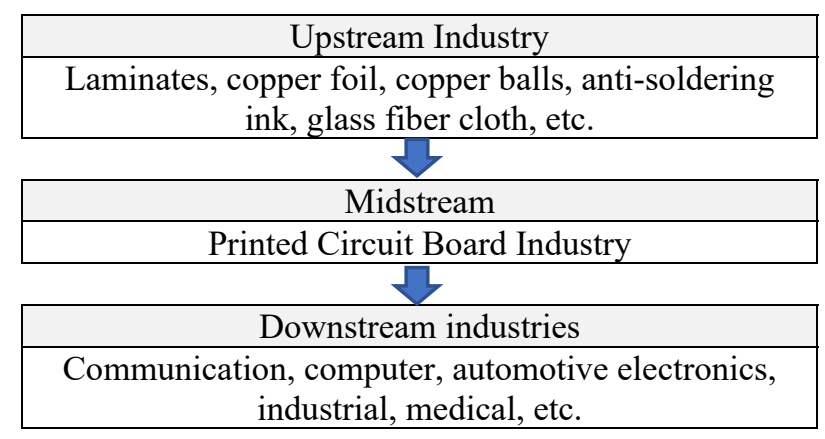

Figure 1 Printed Circuit Board Industry Chain 


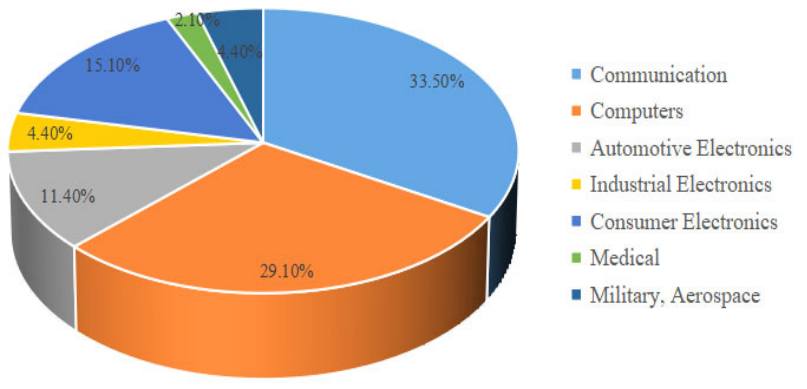

Figure 2 Printed Circuit Board Application Segment Share 2019

\section{PCB production waste liquid and the source of heavy metals}

In the production of PCBs will produce a large number of waste streams, and these waste streams are mainly generated in the wet processing process, the quality of the waste streams are different, and the copper content is different.

Table 1 Sources of wastewater and copper content

\begin{tabular}{|c|c|c|}
\hline $\begin{array}{c}\text { Wastewater } \\
\text { type }\end{array}$ & Primary Sources & $\begin{array}{l}\text { Copper } \\
\text { content }\end{array}$ \\
\hline $\begin{array}{l}\text { Abrasive } \\
\text { plate cleaning } \\
\text { brush water }\end{array}$ & $\begin{array}{l}\text { Steel plate grinding and } \\
\text { brushing line; surface } \\
\text { treatment; ceramic } \\
\text { grinding plate line, etc. }\end{array}$ & $\begin{array}{l}\text { Copper- } \\
\text { containing } \\
\text { powder }\end{array}$ \\
\hline $\begin{array}{l}\text { General } \\
\text { cleaning } \\
\text { water }\end{array}$ & $\begin{array}{l}\text { Inner and outer layer } \\
\text { pre-treatment line. } \\
\text { Inner and outer DES } \\
\text { lines; sinking copper } \\
\text { lines; solder resist } \\
\text { treatment lines; OSP } \\
\text { and floor cleaning, etc. }\end{array}$ & $\begin{array}{l}\text { Contains } \\
\text { ionic } \\
\text { copper }\end{array}$ \\
\hline $\begin{array}{c}\text { Organic } \\
\text { wastewater }\end{array}$ & $\begin{array}{l}\text { Cleaning water for } \\
\text { DES line development, } \\
\text { de-filming, wet film } \\
\text { development, wet film } \\
\text { rinsing, etc.; browning } \\
\text { line; pre-treatment line } \\
\text { and solder resist } \\
\text { development; }\end{array}$ & $\begin{array}{l}\text { Contains } \\
\text { ionic } \\
\text { copper }\end{array}$ \\
\hline $\begin{array}{l}\text { Wastewater } \\
\text { complexation }\end{array}$ & $\begin{array}{c}\text { Immersion } \\
\text { copper/plating/MCP } \\
\text { vertical plating line; } \\
\text { mainly chemical } \\
\text { immersion copper and } \\
\text { its cleaning water, } \\
\text { alkaline etching } \\
\text { cleaning water, } \\
\text { browning after water } \\
\text { washing; }\end{array}$ & $\begin{array}{l}\text { Copper- } \\
\text { containing } \\
\text { complexes }\end{array}$ \\
\hline $\begin{array}{l}\text { Copper } \\
\text { plating } \\
\text { cleaning } \\
\text { water }\end{array}$ & $\begin{array}{l}\text { Cleaning water for } \\
\text { copper plating section }\end{array}$ & $\begin{array}{l}\text { Contains } \\
\text { CuSO4 }\end{array}$ \\
\hline
\end{tabular}

The analysis shows that different types of wastewater contain different copper elements, which should be recovered with corresponding technology and reused after treatment.

\section{Treatment of waste liquid and extraction of copper}

In fact, the printed circuit board (PCB) uses a closed loop system for waste liquid treatment, and the etching master batch discharged from the production line is treated with this system to extract copper ions from the high concentration of copper-containing etchant, and then the low concentration of copper-containing etchant is returned to the production line. In the etching process of circuit boards, the concentration of copper ions in the etchant will continuously increase thus weakening the etching capacity. If you want to make the etchant achieve the best etching capacity, you must keep the copper ions, chloride ions and $\mathrm{PH}$ value in the etchant within a reasonable and stable range. To maintain the optimum concentration of various components in the etchant, it is necessary to continuously add sub-fluid to the etchant to replace the waste etchant that has lost its etching ability. Adding a small amount of supplement to the waste etchant that needs to be discharged to compensate for the part lost due to the etching process will allow the waste solution to be returned to the production line as a new sub-fluid, i.e., regenerated etchant. The etchant can be recycled, and the ammonia wash water can be recycled.

Firstly, starting from finding the factors affecting the copper content after waste liquid treatment, combined with the actual production of enterprises, according to the volume of mother liquor storage tank and the volume of electrolytic tank, a high and low level device is set in the mother liquor storage tank. If the volume of liquid in the mother liquor storage tank is less than the volume of electrolytic tank, the system detects that the mother liquor is insufficient and will stop automatically after the discharge of this mother liquor into the regeneration liquid storage tank after electrolysis, waiting for enterprises to discharge the mother liquor. If there is enough mother liquor in the mother liquor storage tank, the etching liquid after electrolysis will be discharged into the regeneration liquid tank after the electrolysis of the electrolytic tank is completed, and then the mother liquor to be electrolyzed in the mother liquor storage tank will be pumped into the electrolytic tank, and the pumping will be stopped automatically when the electrolytic tank is full, and the automatic electrolysis will start. The cycle continues. The anode plate used in the electrolysis tank is very important. In this project, graphite plate with good corrosion resistance, stable chemical properties, high temperature resistance, corrosion resistance and good electrical conductivity is used as the anode. The cathode uses inexpensive national standard 304 stainless steel plate (or copper plate of the same size), and copper is plated on the stainless steel plate after electrolysis, which can be torn off to form copper foil after a few days. The process of direct electrolysis regeneration cycle is shown in Figure 3. 


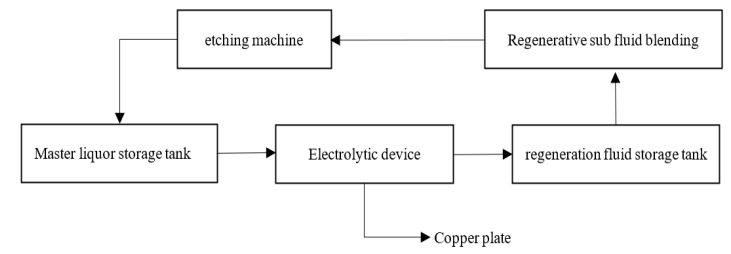

Figure 3 Direct electrolytic regeneration cycle process The anode plate used in the electrolysis of the electrolyzer is crucial, and the graphite plate with stable chemical properties, good high temperature resistance, corrosion resistance and good electrical conductivity is used as the anode in the experiment. The cathode uses inexpensive national standard 304 stainless steel plate (or copper plate of the same size), high concentration of copper-containing waste solution after electrolysis will be copper plated on the stainless steel plate, copper can be torn off from the stainless steel plate after reaching a certain thickness to form a copper foil, as shown in Figure 4, the regenerative recycling of etching waste solution and copper extraction.

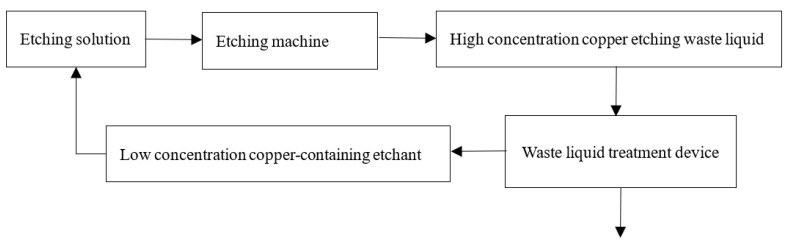

Figure 4 Regenerative recycling of etching waste solution and copper extraction

The reduction of divalent copper ions in solution to copper through the gain and loss of electrons at the cathode, the specific chemical electronic formula is:

The reaction of the cathode is:

$$
\mathrm{Cu}^{2+}+2 e \rightarrow \mathrm{Cu} \mathrm{Cu}^{+}+e \rightarrow C u
$$

The reaction of the anode is:

$$
2 \mathrm{OH}^{-}-2 e \rightarrow \mathrm{O}_{2} \uparrow+\mathrm{H}_{2} \uparrow
$$

Electrolysis tank: tank body, circulation tank, exhaust gas tower and cooling tower, the upper part of the tank body is provided with an exhaust gas tower, the tank body is connected to the circulation tank by a circulation pump and a pipe, the bottom of the tank body is provided with a pipe, the tank body includes a shell, a steel plate and a graphite plate, the cooling pipe is evenly distributed inside the circulation tank, the graphite plate and the steel plate are vertically located inside the tank body, and the graphite plate is connected to the anode of the electrolysis power supply, and the steel plate is connected to the cathode of the electrolysis power supply. The electrolytic power supply is located at the top of the tank, and the diagram of the electrolytic tank is shown in Figure 5 below.

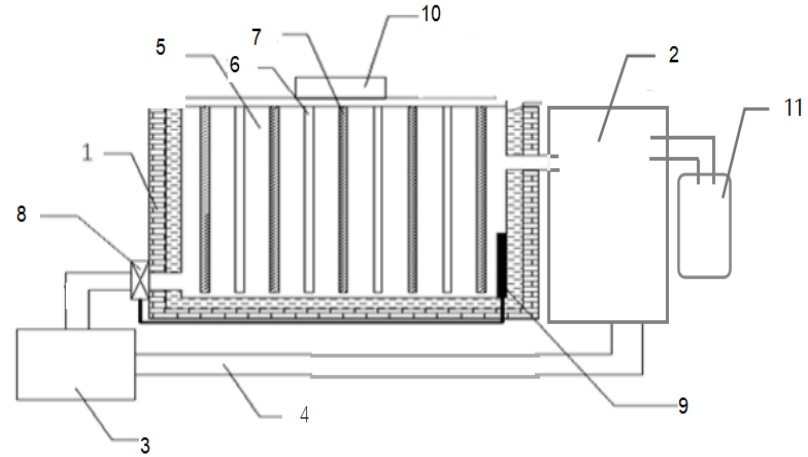

Figure 5 Electrolytic tank

Where: 1-Tank, 2-Circulation tank, 3-Circulation pump, 4-Pipe, 5-Electrolyte, 6-Graphite plate, 7-Steel plate, 8Valve, 9-Electrolyte concentration sensor, 10-Waste gas tower, 11-Cooling tower.

The upper part of the tank 1 is equipped with a waste gas tower, and the tank 1 is connected to the waste gas tower 10 through a pipe, and the bottom of the tank 1 is equipped with a pipe 4 , and the tank 1 is connected to the circulation tank 2 through a circulation pump 3 and the pipe 4, using the circulation flow of electrolyte 5 in the electrolytic tank and the circulation tank, which can effectively improve the electrolysis capacity inside the tank 1 and increase the copper precipitation rate and copper grade. The electrolytic treatment tank 6 is also used to treat the discharged electrolyte 5, which flows into the electrolytic tank after treatment, so that the waste liquid can be recycled, and the density of electrolyte 5 is intelligently controlled by the electrolyte density sensor 9, which achieves an intelligent effect and at the same time reduces costs and increases resource utilization.

The electrolytic tank and circulation tank are used to keep the circulation flow of electrolyte inside the tank, which can effectively improve the electrolytic capacity inside the tank and increase the copper precipitation rate and copper grade, while the electrolytic treatment tank is used to treat the discharged electrolyte, which flows into the circulation tank after treatment, so that the waste liquid can be recycled. To avoid the vaporization of electrolyte, a sealed shell is used to ensure that the air is not polluted and to protect the environment. The graphite plate is used as the anode, which is not easily consumed, and the purity of the copper electrolyzed is very high, basically reaching $99.95 \%$ or more.

Conclusion

In summary, this paper conducts an in-depth study on the treatment of circuit board production waste liquid and copper recovery technology, first analyzing which water quality contains copper in the wastewater discharged from the production line, and then using a closed loop system to treat the etching master batch discharged from the production line using this system, extracting copper ions from the high concentration of copper-containing etchant, and then returning the low concentration of coppercontaining etchant to the production line for recycling. The low concentration copper etchant is then returned to the production line for recycling. This method avoids the pollution to the environment and human beings caused by the waste liquid discharge, and also achieves the maximum utilization of resources. 


\section{Acknowledgements}

This paper is supported by Xi'an Science and technology plan project (2020KJRC0150); Key R \& D plan project of Shaanxi Province (2019GY-038); Shaanxi Province Natural Science Basic Research Program (2021JM-539); Scientific and technological innovation team of computer vision and image processing technology.

\section{References}

1. Liu Houchuan, Qi Jianjian, Lu Zhaohui, Tang Zhengtao, Yu Shaoming. Research progress of printed circuit board etching and copper-containing etching waste liquid treatment technology[J]. Contemporary Chemical Research,2019(15):109110 .

2. Zeng Yifeng. Research on the application of double film process in the treatment technology of Meizhou printed circuit board wastewater[D]. Guangdong University of Technology,2018.

3. Chen Ru. Technical research on copper recovery from printed circuit board etching solution and microetching solution[J]. Automation and Instrumentation,2016(01):11-12.DOI:10.14016.

4. Yang L.H. Technical solutions and engineering application research of PCB wastewater treatment and reuse $[\mathrm{J}]$. Building Materials and Decoration,2017(40):108-109.

5. Luo G, Wu S G, Zheng W Z, Peng Y, Zhang Y. Exploration of wastewater classification treatment process in PCB industrial park [J]. Technology and Innovation,2019(03):110-111. 